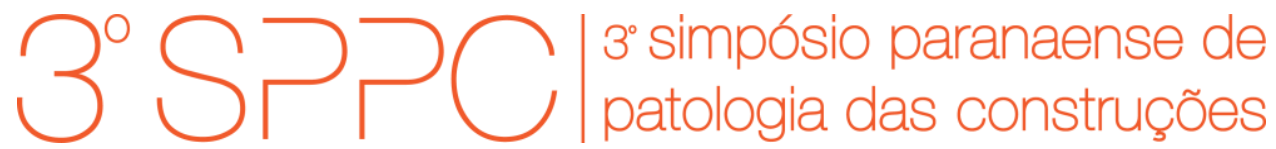

ISSN 2526-7248 artigo n. 3SPPC1021, pp. 233-244, 2018

\title{
Chuva dirigida no estado do Paraná e sua importância para o projeto de fachadas: mudanças ao longo do tempo e comparação entre interior e litoral
}

\author{
Rufato, Leonardo T. ; Baptista, Gustavo D. M. ${ }^{2}$; Giordano, Dominique E. ${ }^{3}$; Mattana, \\ Alécio J. ${ }^{4}$; Medeiros, Marcelo H. F. ${ }^{5}$ \\ ${ }^{1}$ Graduando, Universidade Federal do Paraná, leorufato@gmail.com \\ ${ }^{2}$ Graduando, Universidade Federal do Paraná, gustavo_d_medeiros@hotmail.com \\ ${ }^{3}$ Professora, Instituto Federal do Paraná, domi.giordano@gmail.com \\ ${ }^{4}$ Professor, Instituto Federal do Paraná, alehcio@gmail.com \\ ${ }^{3}$ Professor, Universidade Federal do Paraná, medeiros.ufpr@gmail.com
}

\begin{abstract}
Resumo: Tendo em vista a progressiva preocupação com a durabilidade das construções, torna-se concomitantemente necessário o melhor entendimento da influência das condições ambientais sobre as estruturas. Neste contexto, esta pesquisa visa o estudo do fenômeno de chuva dirigida (chuva associada ao vento) e seu comportamento ao longo dos anos no estado do Paraná, além de sua influência sobre a durabilidade de fachadas de edifícios. A análise realizada foi possível a partir da obtenção dos dados meteorológicos fornecidos pelo Sistema Meteorológico do Paraná de 37 localidades para a faixa de anos de 2006 a 2015, com posterior cálculo dos Índices de Chuva Dirigida (ICDs) Anual e Mensal. Através destes, foi possível a elaboração de mapas de Chuva Dirigida Anual e Chuva Dirigida Mensal Crítica para o estado. A avaliação foi conduzida comparandose mapas de chuva dirigida do Paraná de dois períodos consecutivos, o mais antigo abrangendo de 2006 a 2010, e o mais recente, de 2011 a 2015. Neles fica evidenciado que houveram mudanças importantes de exposição com o passar dos anos nas diferentes regiões do estado e, em especial, que áreas de menor exposição perderam espaço para aquelas de maior exposição. Também foi conduzida parte da investigação focando na quantificação do índice de chuva dirigida de duas localidades litorâneas e três no interior do estado. Observou-se uma tendência de aumento do índice de chuva dirigida com o passar dos anos para estas cinco localidades, porém com magnitudes mais expressivas no interior.
\end{abstract}

Palavras-chave: Índice de Chuva Dirigida, Durabilidade de Fachadas, Mapa do Paraná, Variação Climatológica.

\begin{abstract}
With the rising concern at durability in buildings, it becomes necessary to advance the understanding of environmental conditions influence over structures. This research aims to study the driven rain phenomenon (rain associated with wind) and its behavior throughout the years in the state of Paraná-Brazil, besides its influence over building facades durability. The analysis was accomplished based on meteorological data (from 2006 to 2015) provided by the Paraná Meteorological System, acquired from 37 stations distributed over the state, which provided means to calculate the Annual and Mensal Driven Rain Indexes for each place. Annual Driven Rain and Monthly Critical Driven Rain maps of the state were plotted based on calculated indexes. The evaluation was carried out comparing driven rain maps for two following periods, the former one comprises data from 2006 to 2010 , while the latter comprises from 2011 to 2015 data. The maps signalize that important changes of exposure occurred over the years in different regions of the state and, furthermore, that areas of less exposure contracted while those of superior exposure expanded. In addition to that, part of the analysis focused on the driven rain index of two coastal cities and three countryside cities. A tendency of increase in the driven rain index was observed for all five locations. However, the increase rate was more expressive on the countryside.
\end{abstract}

Keywords: Driven Rain Index, Building Facades Durability, Paraná Map, Climatological Variation. 
RUFATO, L. T. et al., CHUVA DIRIGIDA NO ESTADO DO PARANÁ E SUA IMPORTÂNCIA PARA O PROJETO DE FACHADAS: MUDANÇAS AO LONGO DO TEMPO E COMPARAÇÃO ENTRE INTERIOR E LITORAL. $3^{\circ}$ Simpósio Paranaense de Patologia das Construções (30 SPPC), artigo 3SPPC1021, pp. 233 - 244, 2018. DOI: 10.4322/2526-7248.021

\section{Introdução}

Nas últimas décadas, a durabilidade das construções tem tomado foco crescente de pesquisas na Engenharia Civil. Buscando edificações que mantenham suas condições de segurança e usabilidade por mais tempo, pesquisadores tem objetivado cada vez mais entender os processos de degradação das edificações e como atuar para mitigá-los.

A durabilidade de uma edificação está intimamente relacionada com os agentes ambientais que causam a deterioração dos seus componentes, sendo a chuva uma das principais causas de manifestações patológicas em ambientes externos. Dentro deste contexto está inserido o estudo da Chuva Dirigida, que consiste da precipitação pluviométrica que recebe uma componente horizontal de velocidade pela ação do vento e então passa a cair obliquamente, sendo lançada de encontro à envoltória da edificação. Este é um fenômeno de alta variabilidade, pois é função da matriz de ventos e chuvas de cada região, o que depende diretamente do clima e topografia do local. Devido à isso, a Chuva Dirigida faz com que edificações com fachadas idênticas, mas orientações distintas, ou ainda, fachadas idênticas, mas em localidades distintas, apresentem durabilidade variável às manifestações patológicas causadas por umedecimento.

Diante da importância do tema e buscando seu entendimento cada vez maior, esta pesquisa objetiva o estudo das mudanças ocorridas ao longo do tempo no Paraná quanto ao fenômeno de chuva dirigida, bem como fazer uma comparação desse desenvolvimento entre as porções interior e litoral do estado.

\section{Referencial teórico}

Segundo Blocken e Carmeliet [1], chuva dirigida é a chuva (precipitação pluviométrica) que recebe uma componente de velocidade horizontal pela ação do vento e então passa a cair obliquamente. É a chuva que é carregada pelo vento e, em uma definição mais restrita, é lançada de encontro ao envelope da edificação [2]. Pode ainda ser definida como a quantidade de chuva com uma componente horizontal que passa através de uma superfície vertical pela ação do vento [3].

\subsection{Chuva dirigida e durabilidade de fachadas}

A fachada - como elemento fundamental da envoltória do edifício - age como barreira protetora aos agentes atmosféricos e, assim sendo, sofre com uma das agressões físicas mais importantes: a da água da chuva [4]. Para edificações, a chuva dirigida é uma grande fonte de umidade, afetando seu desempenho higrotérmico e a durabilidade de suas fachadas [3].

De acordo com Choi [5], danos causados pela penetração de água nas fachadas de edifícios tem há tempos sido reconhecidos como um grande problema de manutenção. Estes danos e seus decorrentes prejuízos financeiros podem ser atribuídos à dois tipos de processos. O primeiro está relacionado à penetração de água da chuva para o ambiente interior através das fachadas, causando inconvenientes aos habitantes, danificando acabamentos do edifício e bens em seu interior. O segundo está relacionado à entrada de umidade nos materiais que 
RUFATO, L. T. et al., CHUVA DIRIGIDA NO ESTADO DO PARANÁ E SUA IMPORTÂNCIA PARA O PROJETO DE FACHADAS: MUDANÇAS AO LONGO DO TEMPO E COMPARAÇÃO ENTRE INTERIOR E LITORAL. $3^{\circ}$ Simpósio Paranaense de Patologia das Construções (30 SPPC), artigo 3SPPC1021, pp. 233 - 244, 2018. DOI: 10.4322/2526-7248.021

constituem a envoltória do edifício, danificando-os. O primeiro processo usualmente ocorre em curta duração de tempo e a degradação depende da intensidade da chuva dirigida. Já o segundo mecanismo é um processo de longo prazo e a degradação está relacionada a quantidade total de chuva dirigida ao longo desse período. Ainda como consequência da chuva dirigida, o aumento da umidade nas paredes externas aumenta a condutividade térmica destas, tornando-as mais permeáveis ao calor [6].

$\mathrm{Na}$ ausência de vento, as gotas de chuva cairiam verticalmente e causariam pouco umedecimento dos envoltórios dos edifícios. Contudo, sob a ação da velocidade do vento, o impacto da chuva dirigida em paredes exteriores passa a submeter as fachadas a diferentes níveis de umidade, conforme ilustrado na Figura 1 [7].

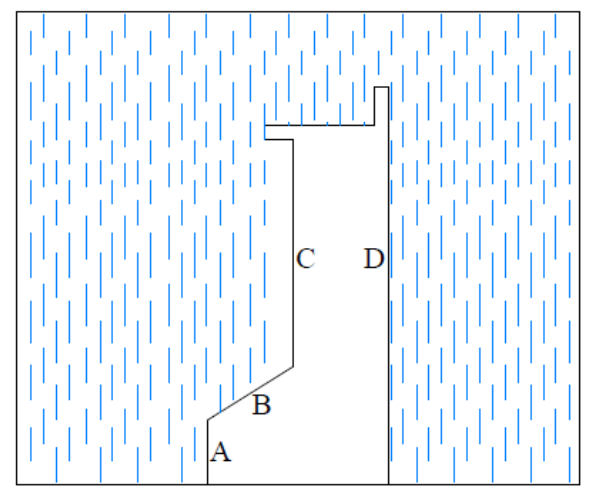

(a)

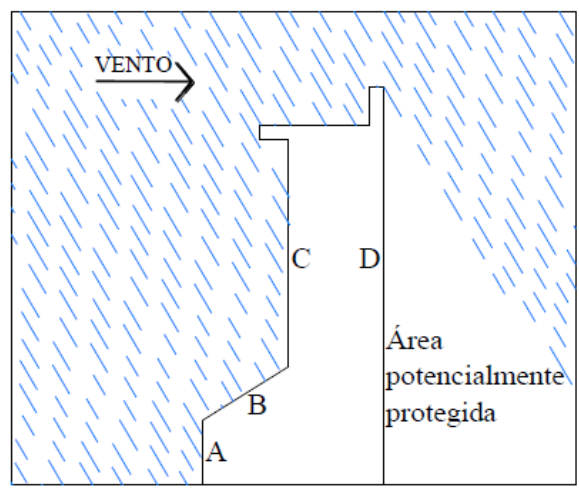

(b)

Figura 1: Influência do vento na direção da chuva dirigida e na exposição das fachadas: (a) Condição sem vento e (b) Condição com vento

De acordo com Giongo, Padaratz e Lamberts [3] e Melo Jr e Carasek [8], os danos causados por esta umidade em abundância vão desde problemas estéticos até degradações profundas. Entre eles estão a proliferação de micro-organismos, a descoloração dos revestimentos, a formação de manchas e eflorescências, a variação dimensional de elementos construtivos, a corrosão eletroquímica dos metais e infiltrações, levando à degradação dos materiais que constituem os componentes das fachadas.

\section{2 Índices de chuva dirigida (ICD anual e ICD mensal)}

A medição direta da chuva dirigida (medição da quantidade de água passando por um plano vertical) claramente seria a maneira mais natural de quantificar cargas de chuva dirigida em diferentes localidades. Contudo, o equipamento necessário para isso (medidor de parede vertical ou "driving rain gauge") não é um equipamento padrão em estações meteorológicas e, portanto, a chuva dirigida não é medida de maneira rotineira [9]. Seria, então, interessante que a chuva dirigida fosse mensurada através de dados usualmente lidos nas estações. Tendo isso em vista, pesquisadores verificaram a relação proporcional entre a quantidade de chuva dirigida e as variáveis climáticas de influência como velocidade do vento, direção do vento e precipitação, estas sendo medidas realizadas em estações meteorológicas padrão, o que conduziu aos métodos semi-empíricos de medição [1]. Estes métodos baseiam-se em relações entre dados de vento e precipitações pluviométricas 
RUFATO, L. T. et al., CHUVA DIRIGIDA NO ESTADO DO PARANÁ E SUA IMPORTÂNCIA PARA O PROJETO DE FACHADAS: MUDANÇAS AO LONGO DO TEMPO E COMPARAÇÃO ENTRE INTERIOR E LITORAL. $3^{\circ}$ Simpósio Paranaense de Patologia das Construções (30 SPPC), artigo 3SPPC1021, pp. 233 - 244, 2018. DOI: 10.4322/2526-7248.021

obtidos de estações meteorológicas para o cálculo da chuva dirigida e suas direções principais [10].

Segundo Blocken e Carmeliet [1], nos anos 60, o CIB (Conseil International du Bâtiment) estabeleceu o índice de chuva dirigida (ICD) como sendo o produto entre a velocidade média do vento e a quantidade total de precipitação, conforme a Eq. 1.

$$
I C D=V \times \frac{P}{1000}
$$

Onde: ICD = índice de chuva dirigida $\left(\mathrm{m}^{2} / \mathrm{s}\right) ; \mathrm{V}=$ velocidade média do vento $(\mathrm{m} / \mathrm{s}) ; \mathrm{P}$ $=$ precipitação total $(\mathrm{mm})$.

Quando o ICD é calculado a partir de médias anuais de velocidade do vento e de precipitação acumulada anual (ou seja, baseando-se em dados de anos completos) ele é denominado ICD anual (ICDa), sendo este um método razoavelmente preciso para comparação entre o total acumulado de chuva dirigida em paredes de diferentes localidades [3]. Dessa forma, este parâmetro é importante como um critério global de balizamento de projetos de fachadas de edifícios de modo a tornálas mais duráveis, embora não seja comumente considerado na prática de projeto [10].

Já quando se faz uso de dados de precipitação e velocidade média de vento mensais, é ainda possível calcular índices de chuva dirigida mensais (ICD mensais) e fazer uma análise do comportamento da chuva dirigida durante o ano [3]. Com isso, pode-se verificar qual é a chuva dirigida crítica que um local recebe, ou seja, qual é a carga máxima de chuva dirigida que uma edificação será submetida ao longo dos meses de um ano, definindo-se então o ICD crítico, que é numéricamente igual ao maior ICD mensal do ano. Esse valor pode ainda ser utilizado como a carga máxima de projeto da edificação [10]. Levando em conta este índice, dimensiona-se a fachada para o pior caso (pelo pico), haja visto que este pico não é diluído na média por meses de menor chuva dirigida, como acontece no ICDa.

\subsection{Classes de exposição}

Com a finalidade de gerar parâmetros de referência para classificar o nível de impacto da chuva dirigida em uma localidade quanto ao índice de chuva dirigida (ICD), foram criadas por pesquisadores faixas distintas de exposição. Com isso, a partir do ICD anual, pode-se classificar uma localidade quanto ao seu grau de exposição.

A primeira classificação foi proposta por Lacy [11], englobando três faixas (Protegido, Moderado e Severo), de acordo com ICDa da localidade. Posteriormente, Marsh [12] propôs uma adaptação à classificação de Lacy. Nesta, os graus de exposição incluem localidades que possuem distância do mar, ou estuários, menor que 8 quilômetros, conforme ilustrado na Figura 2.

Em 2002, Chand e Bhargava propuseram uma nova faixa de classificação no critério de Lacy [11], haja vista os altos índices de chuva dirigida encontrados na Índia. A Figura 2 mostra a classificação proposta. 
RUFATO, L. T. et al., CHUVA DIRIGIDA NO ESTADO DO PARANÁ E SUA IMPORTÂNCIA PARA O PROJETO DE FACHADAS: MUDANÇAS AO LONGO DO TEMPO E COMPARAÇÃO ENTRE INTERIOR E LITORAL. 30 Simpósio Paranaense de Patologia das Construções (30 SPPC), artigo 3SPPC1021, pp. 233 - 244, 2018. DOI: 10.4322/2526-7248.021

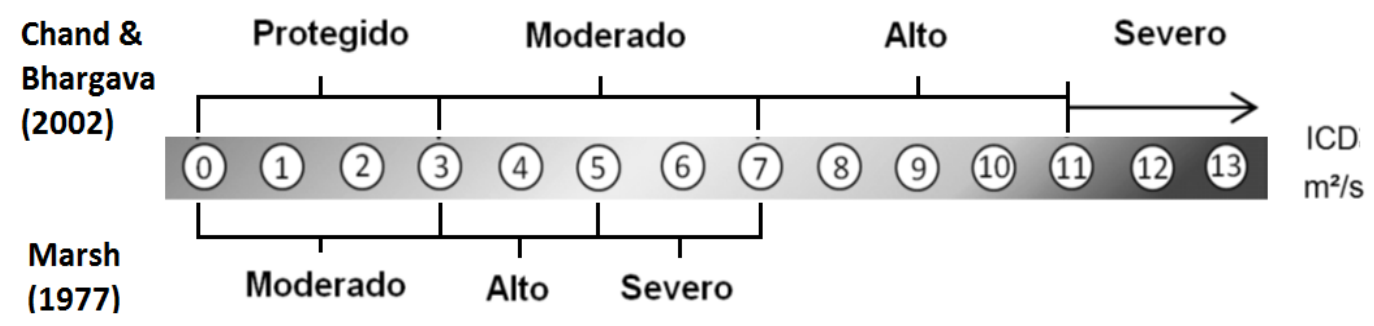

Figura 2: Classificação segundo o grau de exposição por Marsh [12] e Chand e Bhargava [6]

Por se tratar de uma classificação mais recente e dividir em mais faixas de classificação, nesta pesquisa será utilizado o critério de Chand e Bhargava [6], com exceção de cidades litorâneas, em que utilizou-se a classificação proposta por Marsh [12]. Vale ainda apontar que uma maneira prática de se apresentar o grau de exposição atuante em uma região é através de um mapa de chuva dirigida, de modo que esta prática foi abordada neste trabalho.

\section{Metodologia}

Na presente pesquisa fez-se uso do método de cálculo semi-empírico, que consiste na análise de dados de precipitação e velocidade do vento. Os objetos de estudo foram no total 37 localidades do Paraná, cujo dados meteorológicos foram obtidos do Sistema Meteorológico do Paraná (SIMEPAR), para uma série histórica de Janeiro de 2006 a Dezembro de 2015. Os dados obtidos consistem de valores diários de precipitação (em milímetros de chuva) e velocidade média do vento $(\mathrm{m} / \mathrm{s})$.

Através da Equação 1 e fazendo uso de dados de velocidade média anual do vento e precipitação acumulada anual (lembrando que é necessário desconsiderar dias de precipitação nula, visto que para que ocorra chuva dirigida é necessário que haja precipitação), pôde-se calcular os ICD anuais de cada localidade.

Com o intuito de constatar mudanças na chuva dirigida ao longo da série histórica de 10 anos estudada, um mapa referente ao período de 2006 a 2010 foi plotado e comparado com outro mapa, que considera dados de 2011 a 2015 - dois períodos de 5 anos cada. Colocando estes mapas lado a lado (ambos fazendo uso de uma mesma escala de cores) pôde-se observar a evolução da chuva dirigida anual no estado do Paraná.

Ainda para comparar a evolução da Chuva Dirigida entre interior e litoral, foi conduzida uma parte da investigação focando no desenvolvimento ano a ano do índice de chuva dirigida anual em duas localidades litorâneas (Antonina e Guaratuba) e em três cidades localizadas no interior do estado (Curitiba, Londrina e Maringá). Colocando os gráficos de linha obtidos para as duas regiões lado a lado e comparando os coeficientes angulares das linhas de tendência de primeiro grau para cada cidade, pôde-se realizar análises comparativas entre a evolução da chuva dirigida anual no interior e no litoral.

O cálculo também foi realizado para 32 localidades considerando uma divisão de dados mensal. Para este caso, foram calculadas a soma da precipitação mensal e a velocidade média mensal do vento, de modo a obter as variáveis para a Equação 1 
RUFATO, L. T. et al., CHUVA DIRIGIDA NO ESTADO DO PARANÁ E SUA IMPORTÂNCIA PARA O PROJETO DE FACHADAS: MUDANÇAS AO LONGO DO TEMPO E COMPARAÇÃO ENTRE INTERIOR E LITORAL. $3^{\circ}$ Simpósio Paranaense de Patologia das Construções (30 SPPC), artigo 3SPPC1021, pp. 233 - 244, 2018. DOI: 10.4322/2526-7248.021

e estabelecer os ICD mensais. Selecionando os máximos valores de ICD mensal ao longo de cada um dos anos, obtiveram-se os ICD críticos de cada ano para cada uma das 32 localidades.

Com o intuito de constatar mudanças na chuva dirigida crítica ao longo da série histórica de 10 anos estudada, novamente um mapa referente ao período de 2006 a 2010 foi plotado e comparado com outro mapa, que considera dados de 2011 a 2015. Colocando estes mapas lado a lado (ambos fazendo uso de uma mesma escala de cores) pôde-se verificar mudanças da chuva dirigida crítica no Paraná ao longo da série histórica analisada.

Todos os mapas foram plotados através de um software de mapeamento, modelagem e análise de dados, pela interpolação de dados baseado no método de crigagem.

\section{Resultados}

\subsection{ICD anual - mudança da chuva dirigida anual ao longo do tempo}

Com dados de ICDa médio separados entre os períodos de 2006-2010 e 20112015, foram plotados os mapas representados nas Figuras 3 e 4.

Comparando estes mapas, pode-se verificar que áreas de menor ICDa perderam espaço para áreas de maior ICDa em todas as regiões à oeste da Serra do Mar, com exceção de uma faixa nos arredores de Cândido de Abreu e Telemaco Borba e uma região no entorno de Fernandes Pinheiro, que permaneceram em um patamar de ICDa entre 2 e $3 \mathrm{~m}^{2} / \mathrm{s}$. Regiões de máximos e mínimos locais, como Apucarana, Cascavel, Entre Rios e UHE Salto Osório também tiveram elevação em seus valores de ICDa. Já a região litorânea - à leste da Serra do Mar - apresentou pouca mudança. Desse modo, pode-se constatar que houve um avanço da Chuva Dirigida Anual na parte interior do Paraná com o passar dos anos, ao passo que no litoral não houve aumento significativo.

Na Figura 5 observa-se esta evolução do ICDa ao longo dos anos para as três maiores cidades do estado - que são interioranas - e na Figura 6 a evolução do ICDa para duas cidades do litoral (as únicas das quais se tinham os dados de toda a série histórica). Percebe-se que as três cidades do interior apresentaram uma tendência de crescimento na chuva dirigida anual, passando de um patamar mais protegido para um moderado. Já para as cidades do litoral, esta tendência não é tão expressiva, mesmo que Guaratuba tenha transitado entre os patamares severo e alto. Isto pode ser reforçado observando-se os coeficientes angulares das linhas de tendência de primeiro grau, utilizadas para aproximar um comportamento médio para cada cidade. Ao passo que para as cidades do interior os coeficientes angulares apresentam grandeza de uma casa decimal após a vírgula, os coeficientes angulares para as cidades do litoral apresentam grandeza de duas casas após a vírgula. Isso indica que a chuva dirigida anual cresceu à uma taxa maior nas cidades interioranas analisadas do que nas cidades litorâneas analisadas. 
RUFATO, L. T. et al., CHUVA DIRIGIDA NO ESTADO DO PARANÁ E SUA IMPORTÂNCIA PARA O PROJETO DE FACHADAS: MUDANÇAS AO LONGO DO TEMPO E COMPARAÇÃO ENTRE INTERIOR E LITORAL. $3^{\circ}$ Simpósio Paranaense de Patologia das Construções (30 SPPC), artigo 3SPPC1021, pp. 233 - 244, 2018. DOI: 10.4322/2526-7248.021

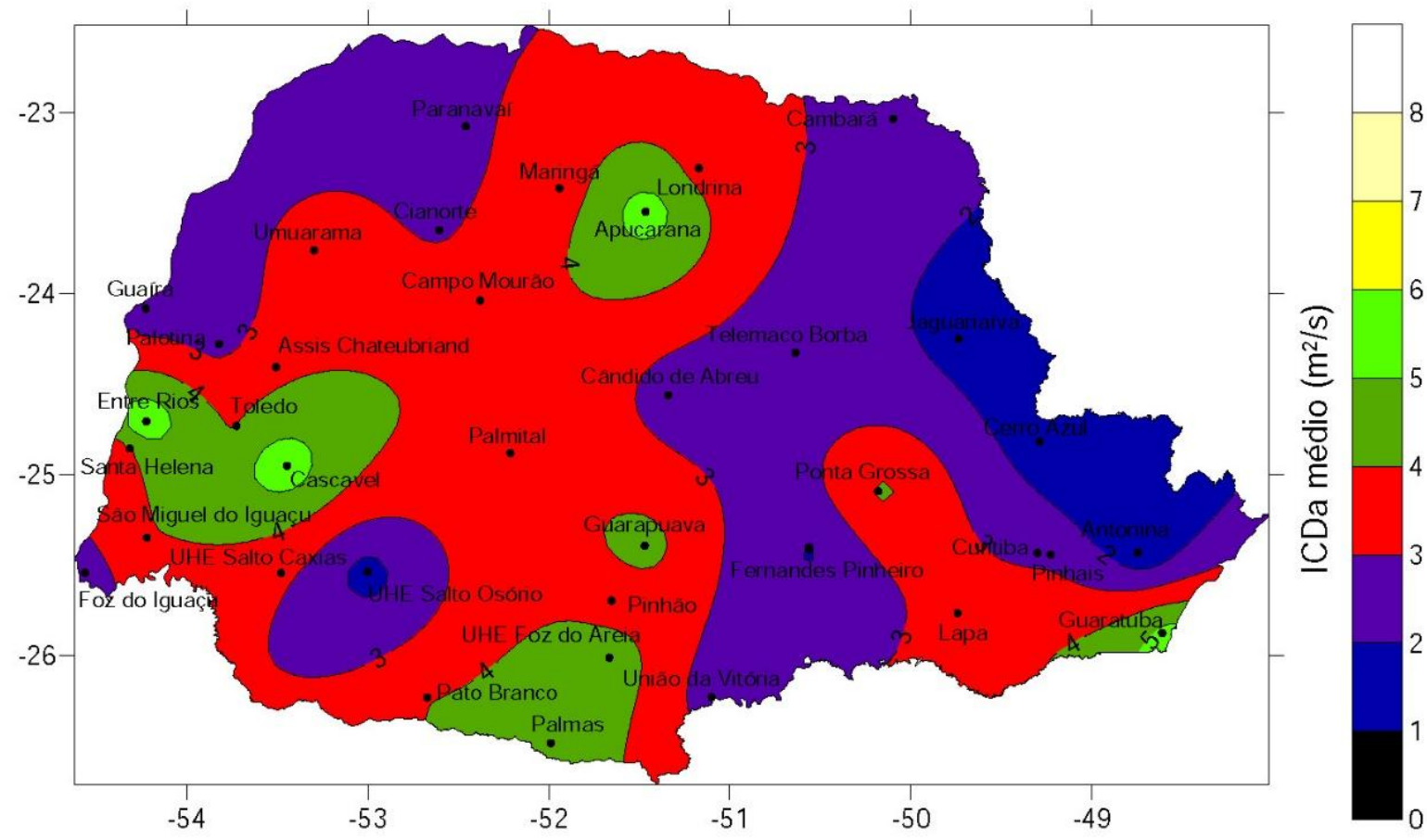

Figura 3: Mapa de Chuva Dirigida Anual (2006-2010). ICDa médio máx=5,927 m²/s

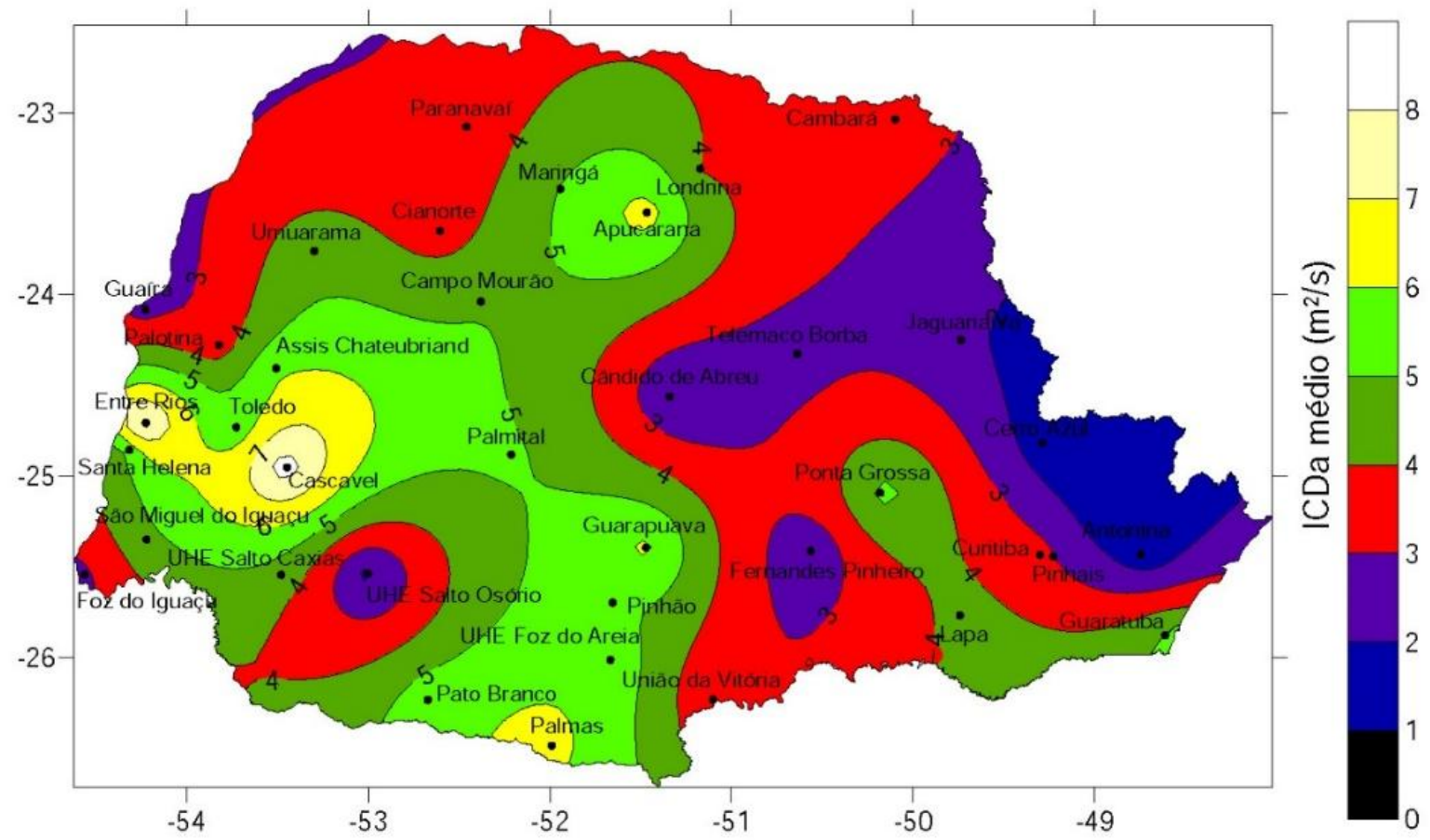

Figura 4: Mapa de Chuva Dirigida Anual (2011-2015). ICDa médio máx=8,599 m²/s

Para uma análise mais precisa seria importante o uso de um período de dados mais longo, buscando entender melhor o comportamento climático das cidades, e, consequentemente, propiciar uma análise mais completa. 
RUFATO, L. T. et al., CHUVA DIRIGIDA NO ESTADO DO PARANÁ E SUA IMPORTÂNCIA PARA O PROJETO DE FACHADAS: MUDANÇAS AO LONGO DO TEMPO E COMPARAÇÃO ENTRE INTERIOR E LITORAL. $3^{\circ}$ Simpósio Paranaense de Patologia das Construções (30 SPPC), artigo 3SPPC1021, pp. 233 - 244, 2018. DOI: 10.4322/2526-7248.021

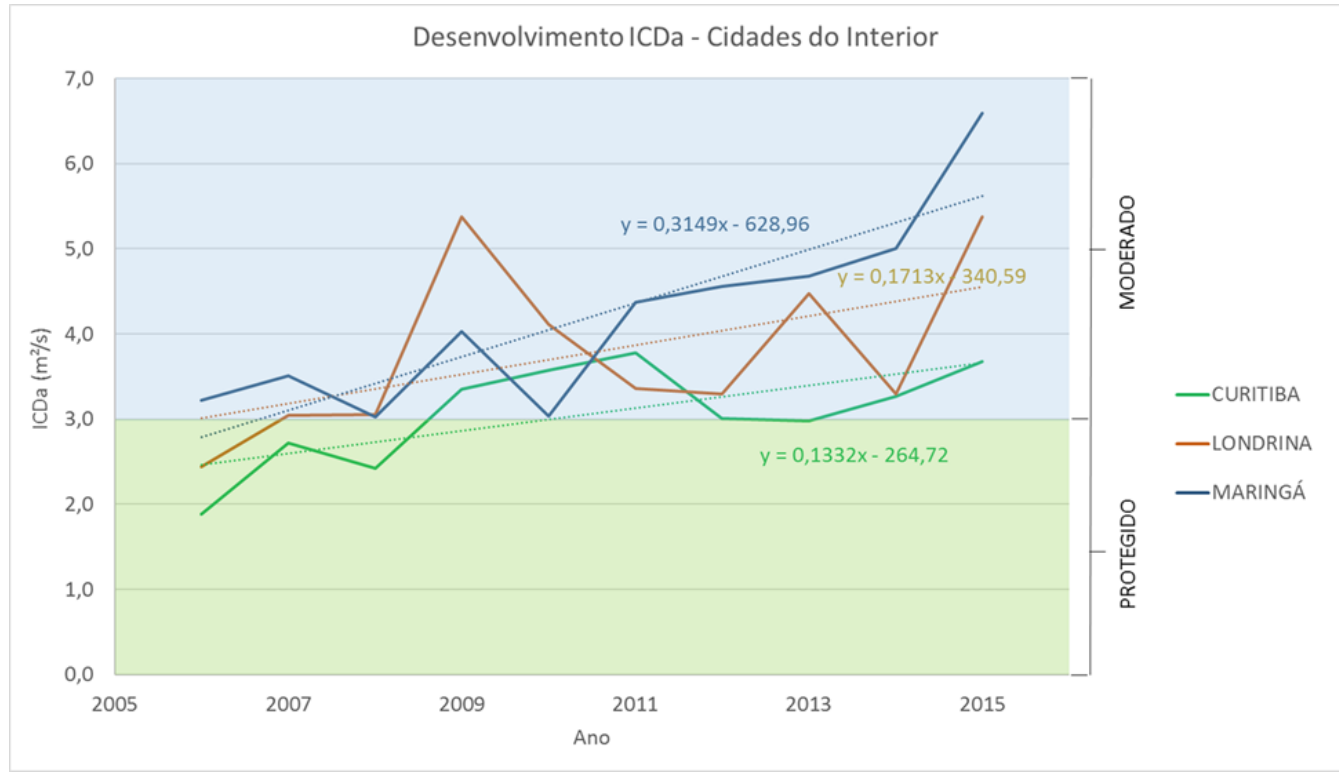

Figura 5: Variação do ICDa em Curitiba, Londrina e Maringá - Interior - Classificação Chand \& Bhargava

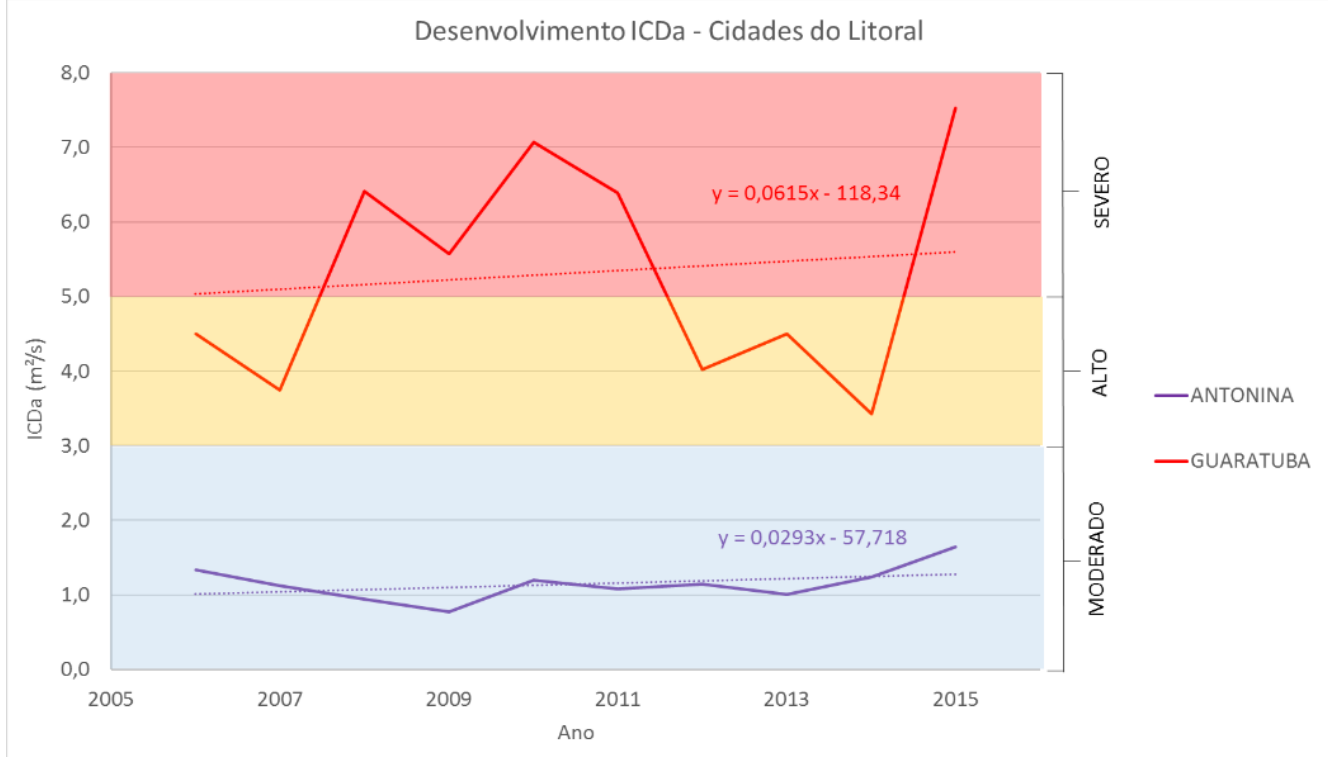

Figura 6: Variação do ICDa em Antonina e Guaratuba - Litoral - Classificação Marsh

\subsection{ICD mensal - mudança da chuva dirigida crítica ao longo do tempo}

Com dados de ICD crítico médio separados entre os períodos de 2006-2010 e 20112015, foram plotados os mapas mostrados nas Figuras 7 e 8. 
RUFATO, L. T. et al., CHUVA DIRIGIDA NO ESTADO DO PARANÁ E SUA IMPORTÂNCIA PARA O PROJETO DE FACHADAS: MUDANÇAS AO LONGO DO TEMPO E COMPARAÇÃO ENTRE INTERIOR E LITORAL. 30 Simpósio Paranaense de Patologia das Construções (30 SPPC), artigo 3SPPC1021, pp. 233 - 244, 2018. DOI: 10.4322/2526-7248.021

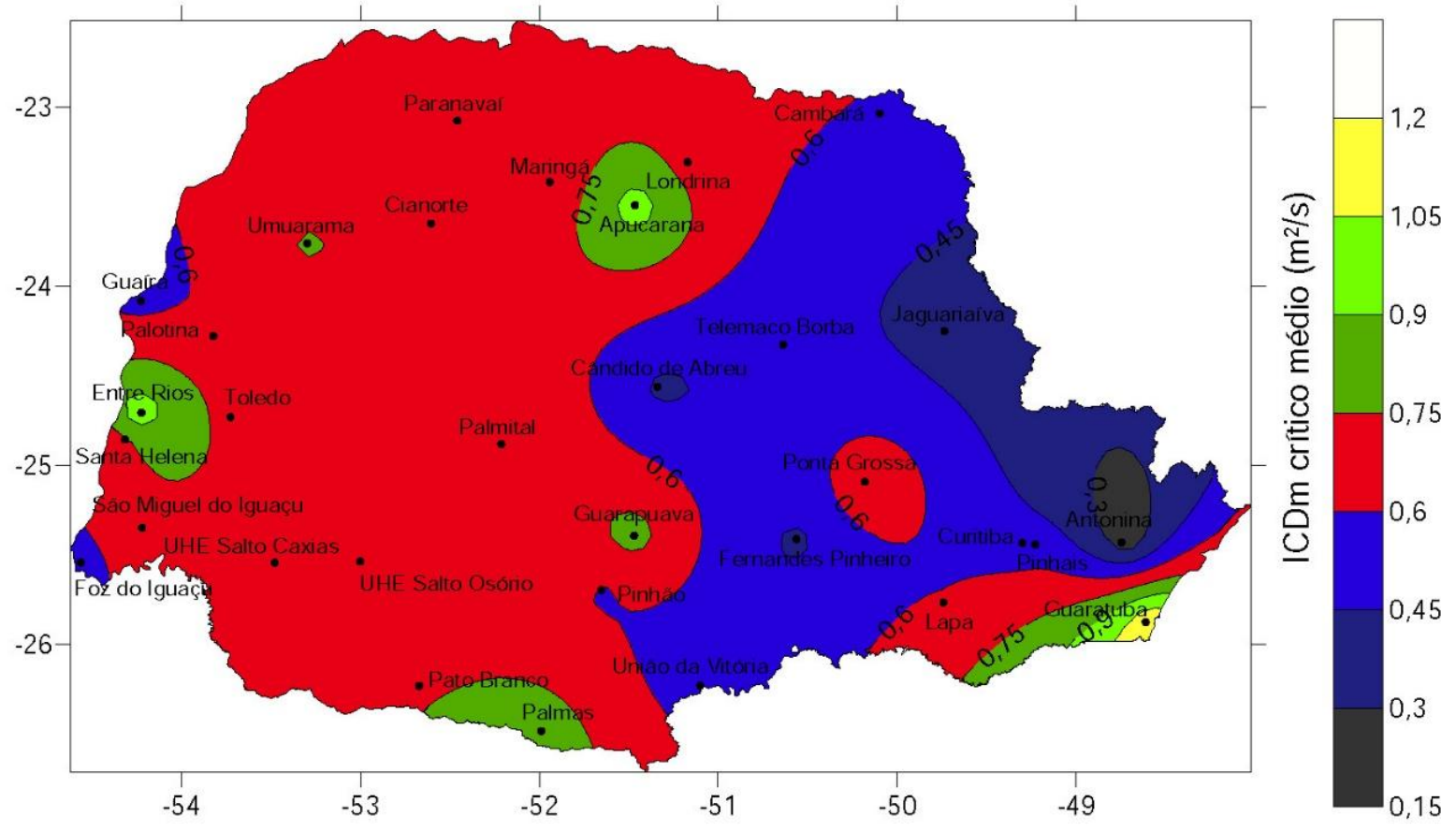

Figura 7: Mapa de Chuva Dirigida Crítica (2006-2010). ICDm crítico médio máx=1,207 m²/s

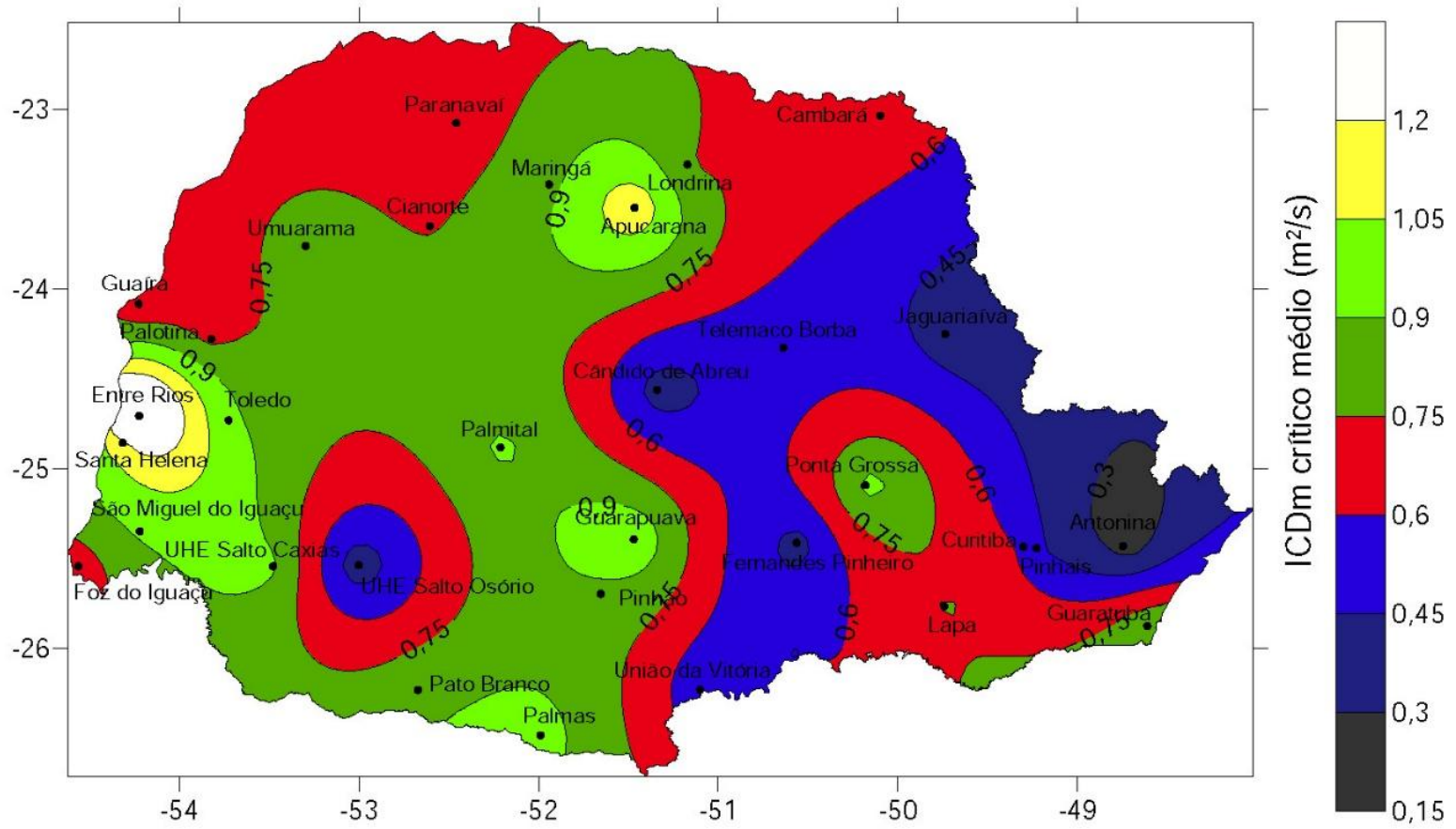

Figura 8: Mapa de Chuva Dirigida Crítica (2011-2015). ICDm crítico médio máx=1,663 $\mathrm{m}^{2} / \mathrm{s}$

Comparando estes dois mapas, pode-se verificar que áreas de menor ICD crítico perderam espaço para áreas de maior ICD crítico, sobretudo nas regiões a oeste do meridiano $-51^{\circ}$, com exceção de uma porção no noroeste do estado (em que a 
RUFATO, L. T. et al., CHUVA DIRIGIDA NO ESTADO DO PARANÁ E SUA IMPORTÂNCIA PARA O PROJETO DE FACHADAS: MUDANÇAS AO LONGO DO TEMPO E COMPARAÇÃO ENTRE INTERIOR E LITORAL. $3^{\circ}$ Simpósio Paranaense de Patologia das Construções (30 SPPC), artigo 3SPPC1021, pp. 233 - 244, 2018. DOI: 10.4322/2526-7248.021

chuva dirigida crítica permaneceu aproximadamente constante). A mesma tendência de expansão de áreas de maior ICD crítico se deu na faixa entre Lapa e Ponta Grossa. Já nas regiões nordeste (na faixa que se estende entre Cândido de Abreu, Telemaco Borba e Jaguariaíva, com começo desde União da Vitória e Fernandes Pinheiro) e litorânea alterações se deram em menor grau. Diferente da região em que se encontra, nos entornos da usina hidroelétrica de Salto Osório houve uma diminuição na chuva dirigida crítica. Diante disso, pode-se constatar que houve um aumento da Chuva Dirigida Crítica em grandes porções do estado com o passar dos anos, sobretudo na parte interior. Desse modo, pode-se dizer que a carga máxima de chuva dirigida que uma edificação será submetida ao longo do ano está com tendência de aumento em grande parte do estado.

\section{Conclusões}

Através dos dados meteorológicos obtidos do SIMEPAR pôde-se calcular o índice de chuva dirigida anual e o índice de chuva dirigida crítico de cada ano da série histórica análisada (que vai de 2006 a 2015) para as localidades em estudo. Através destes resultados, foi possível a elaboração de mapas de chuva dirigida anual e chuva dirigida crítica para o Paraná referentes a diferentes períodos.

Comparando os mapas de chuva dirigida anual - um mapa referente ao período de 2006 a 2010 e outro que considera dados de 2011 a 2015, pôde-se verificar mudanças na chuva dirigida anual ao longo da série histórica estudada. Áreas de menor ICDa se tornaram regiões com maior ICDa em todas as regiões à oeste da Serra do Mar, exceto uma faixa nos arredores de Cândido de Abreu e Telemaco Borba e uma área no entorno de Fernandes Pinheiro, que permaneceram em um patamar de ICDa entre 2 e $3 \mathrm{~m}^{2} / \mathrm{s}$. Regiões de máximos e mínimos, como Apucarana, Cascavel, Entre Rios e UHE Salto Osório também tiveram elevação em seus valores de ICD anual. Porém, na região litorânea houve pouca mudança no ICDa. Desse modo, concluiu-se que houve um aumento da Chuva Dirigida Anual na parte interior do Paraná com o passar dos anos, ao passo que no litoral não houve avanço significativo. Esse parecer foi reforçado focando no desenvolvimento ano a ano do índice de chuva dirigida anual em duas localidades litorâneas (Antonina e Guaratuba) e em três cidades localizadas no interior do estado (Curitiba, Londrina e Maringá). Comparando os gráficos de linha obtidos para as duas regiões (interior e litoral), observando o comportamento de cada cidade e comparando os coeficientes angulares das linhas de tendência lineares para cada localidade, verificou-se que a chuva dirigida anual cresceu à uma taxa maior nas cidades interioranas analisadas do que nas cidades litorâneas analisadas. Ainda, constatou-se que as três maiores cidades paranaenses apresentaram tendência de passar de um nível de exposição mais protegido para um moderado ao longo dos anos.

No momento de elaboração de projetos de fachadas, além do nível de exposição da cidade como um todo (ICDa), o ICD crítico deve ser levado em consideração, pois corresponde à maior incidência de chuva dirigida que a edificação vai receber durante todo o ano, podendo ainda ser utilizado como a carga máxima de projeto para chuva dirigida da edificação. Comparando os mapas de chuva dirigida crítica (um mapa referente ao período de 2006 a 2010 e outro que considera dados de 2011 a 2015), pôde-se verificar mudanças na chuva dirigida crítica ao longo da série histórica estudada. Comparando estes mapas, constatou-se que áreas de menor 
ICD crítico perderam espaço para áreas de maior ICD crítico, sobretudo nas regiões a oeste do meridiano $-51^{\circ}$. Nas regiões nordeste (na faixa que se estende entre Cândido de Abreu, Telemaco Borba e Jaguariaíva) e litorânea as alterações se deram em menor grau. Diante disso, pôde-se concluir que houve um aumento da Chuva Dirigida Crítica em grandes áreas do Paraná com o passar dos anos, sobretudo na parcela interior do estado.

Tendo em vista que a chuva dirigida é um fenômeno climático, esta encontra-se sujeita a anos atípicos e variações imprevisíveis. Em decorrência dessas variações já esperadas, é recomendado que avaliações sejam feitas preferencialmente com séries históricas de 10 a 30 anos, ou no mínimo 5 anos, pois senão o nível real de exposição de uma localidade pode ficar subestimado ou superestimado [3]. Em razão disso, pode-se concluir que a série de dados tomada para análise foi consistente para avaliação das localidades, pois é composta de 10 anos. Contudo, recomenda-se que os índices nesta pesquisa calculados sejam atualizados ano após ano pela alimentação com novos dados, buscando sempre informações mais completas e que se aproximem ao máximo da realidade das cargas de chuva dirigida que uma edificação futura será imposta ao longo de toda sua vida útil, além de permitir uma análise mais precisa sobre as mudanças ao longo do tempo. Por fim, um estudo com maior número de amostras no litoral para comparação de desenvolvimento da chuva dirigida entre interior e litoral seria recomendado.

\section{Agradecimentos}

Esta pesquisa é fruto de iniciação cintífica promovida e patrocinada pelo Conselho Nacional de Desenvolvimento Científico e Tecnológico (CNPq). Fica o agradecimento ao $\mathrm{CNPq}$ pelo apoio e viabilização da pesquisa. Esta iniciação científica teve a orientação do Professor Doutor Marcelo Henrique Farias de Medeiros, professor adjunto da Universidade Federal do Paraná (UFPR) e líder do Grupo de Pesquisa Patologia e Reabilitação das Construções, grupo este instituído na UFPR e ao qual esta pesquisa está ligada. Fica o profundo agradecimento ao Prof. Dr. Marcelo Medeiros pelo apoio e viabilização da pesquisa, e também ao Grupo de Pesquisa Patologia e Reabilitação das Construções e à alma mater Universidade Federal do Paraná.

\section{Referências bibliográficas}

[1] Blocken, B.; Carmeliet, J. (2004) A review of wind-driven rain research in building science. Journal of Wind Engineering and Industrial Aerodynamics, 92, 13: 10791130.

[2] Mook, F. J. R. (2003) Driving rain on building envelopes. Bouwstenen series of the Faculty of Architecture, Planning and Building of the Eindhoven University of Technology.

[3] Giongo, M.; Padaratz, I. J.; Lamberts, R. (2011) Determinação da exposição à chuva dirigida em Florianópolis, SC: índices de chuva dirigida e metodos semiempíricos. Ambiente Construído, 11, 1: 7-23.

[4] Poyastro, P. C. (2011) Influência da volumetria e das condições de entorno da edificação no manchamento e infiltração de água em fachadas por ação de 
RUFATO, L. T. et al., CHUVA DIRIGIDA NO ESTADO DO PARANÁ E SUA IMPORTÂNCIA PARA O PROJETO DE FACHADAS: MUDANÇAS AO LONGO DO TEMPO E COMPARAÇÃO ENTRE INTERIOR E LITORAL. $3^{\circ}$ Simpósio Paranaense de Patologia das Construções (30 SPPC), artigo 3SPPC1021, pp. 233 - 244, 2018. DOI: 10.4322/2526-7248.021

chuva dirigida. Dissertação (Mestrado), Escola de Engenharia, Universidade Federal do Rio Grande do Sul (UFRGS), Porto Alegre, Brasil.

[5] Choi, E. C. C. (1999) Wind-driven rain on building faces and the driving-rain index. Journal of Wind Engineering and Industrial Aerodynamics, 79, 1-2: 105122.

[6] Chand, I; Bhargava, P. K. (2002) Estimation of driving rain index for India. Building and Environment, 37, 5: 549-554.

[7] Thomaz, E. (1990) Manual Técnico de Alvenaria: patologia. 1ed. São Paulo: Projeto, 1990.

[8] Melo Junior, C. M.; Carasek, H. (2011) Índices de chuva dirigida direcional e análise do nível de umedecimento em fachadas de edifício multipavimento em Goiânia, GO. Ambiente Construído, 11, 3: 23-37.

[9] Rydock, J. P.; Liso, K. R.; Forland, E. J.; Nore, K.; Thue J. V. (2005) A driving rain exposure index for Norway. Building and Environment, 40, 11: 1450-1458.

[10] Tomaz, T. P.; Bill, G. H.; Giordano, D. E.; Pereira, E.; Medeiros, M. H. F. (2014) Índice de Chuva Dirigida para o Estado do Paraná: uma ferramenta para projeto de fachadas. In: Lúcia Bressiani; Cristiano Poleto. (Org.). Tópicos Especiais em Construção Civil. 1ed. Toledo, Paraná, p. 107-122.

[11] Lacy, R. E. (1977) Climate and Building in Britain: building research establishment. Her Majesty's Stationery Office, Londres, Inglaterra.

[12] Marsh, P. (1977) Air and Rain Penetration of Buildings. The Construction Press, Londres, Inglaterra. 